\title{
Arte popular na região fronteiriça Brasil-Paraguai
}

\author{
Popular art in the Brazil-Paraguay border region
}

Arte popular en la región fronteriza Brasil-Paraguay

\author{
Paulo César Antonini de Souza ${ }^{1}$; Maria Carolina Rodrigues ${ }^{2}$ \\ Universidade Federal de Mato Grosso do Sul, UFMS, CaMpo Grande-MS, Brasil
}

\begin{abstract}
RESUMO
Este artigo descreve o percurso investigativo originado por uma pesquisa vinculada ao Programa Institucional de Bolsas de Iniciação Científica - PIBIC desenvolvida no biênio 2016/2017, objetivando compreender a inexistência de artistas visuais bidimensionais na região de fronteira seca, situada no encontro entre Ponta Porã e Pedro Juan Caballero. Com abordagem qualitativa e condução fenomenológica, a pesquisa situada abarcou o período de 04 a 10 de abril de 2017 e se fundamentou pela análise do conteúdo de cinco Diários de Campo, considerando o registro de conversas desenvolvidas com seis interlocutores em atuação na área de artes. Os resultados da investigação denotam quatro elementos que podem auxiliar a superar os fatores da inexistência de artistas populares bidimensionais naquela região, promovendo um espaço que os acolha e considere.
\end{abstract}

Palavras-chave: Artistas Populares. Fronteira Seca. Epistemologia. Intencionalidade.

\begin{abstract}
This article describes the course of a research originated from the Programa Institucional de Bolsas de Iniciação Científica - PIBIC developed in the 2016/2017, in order to understand the absence of bidimensional visual artists in the border region between Ponta Porã and Pedro Juan Caballero. Using a qualitative approach of phenomenological conduct, the situated research it happened in April 4 to 10, 2017 and was based on the analysis of the content of five Field Diaries, considering notes of conversations developed with six interlocutors working in the arts. The research results indicate four elements that can help overcome the lack of bidimensional popular artists in that region, promoting a space that welcomes and considers them.
\end{abstract}

Keywords: Popular Artists. Dry Frontier. Epistemology. Intentionality.

\section{RESUMEN}

Este artículo describe el camino de investigación originado por una investigación vinculada al Programa Institucional de Bolsas de Iniciação Científica - PIBIC, desarrollada en el bienio 2016/2017, con el objetivo de comprender la inexistencia de artistas visuales bidimensionales en la región de la frontera seca, ubicada en la reunión entre Ponta Porã y Pedro Juan Caballero. Con un enfoque cualitativo y una conducción fenomenológica, la investigación abarcó el período del 4 al 10 de abril de 2017 y se basó en el análisis de contenido de cinco diarios de campo, considerando las anotaciones. Se desarrollaron conversaciones con seis interlocutores que trabajan en el área de las artes. Los resultados de la investigación denotan cuatro elementos que pueden ayudar a superar los factores de la ausencia de artistas populares bidimensionales en esa región, promoviendo un espacio que los acoge y los considera.

Palabras clave: Artistas Populares. Frontera Seca. Epistemología. Intencionalidad.

\footnotetext{
${ }^{1}$ Professor nos cursos de Artes Visuais da Faculdade de Artes, Letras e Comunicação (FAALC) da UFMS. Líder do Núcleo de Investigação de Fenomenologia em Artes (NINFA/UFMS). E-mail: pauloantonouza@gmail.com

${ }^{2}$ Bacharel em Artes Visuais pela UFMS. Membro do NINFA/UFMS. E-mail: maria.artes95@ gmail.com
} 


\section{INTRODUÇÃO}

Este artigo se ordena a partir de uma investigação desenvolvida durante o biênio 2016-2017 a fim de identificar manifestações da arte popular na região fronteiriça de Mato Grosso do Sul com o Paraguai, especificamente, a partir das relações entre Ponta Porã (BR) e Pedro Juan Caballero (PY). Uma das premissas que originou a presente investigação tem por base o discurso recorrente no estado de Mato Grosso do Sul, onde se atribui uma identidade fronteiriça à produção artística da região.

Parte de uma investigação maior iniciada em 2015, organizada por um projeto de pesquisa (SOUZA, 2014a) autorizado pela Universidade Federal de Mato Grosso do Sul e desenvolvida com a participação de integrantes do Núcleo de Investigação de Fenomenologia em Artes (NINFA/UFMS), o plano de trabalho elaborado para a condução deste recorte vinculou-se ao Programa Institucional de Bolsas de Iniciação Científica - PIBIC, da mesma instituição. Com abordagem qualitativa (BOGDAN; BIKLEN, 1994) e condução fenomenológica (MERLEAU-PONTY, 2006), a pesquisa situada em Ponta Porã para registro dos dados abarcou o período de 04 a 10 de abril de 2017.

Para compreender a abordagem conceitual utilizada nesta investigação, destacamos que a utilização do termo popular associado à palavra arte, implica questões que envolvem fundamentalmente uma origem econômica das mulheres e dos homens responsáveis pela materialização dessas produções, mas também considera a intencionalidade engajada (SOUZA, 2014b) das criações que tornam visíveis as relações sensíveis que os seres humanos organizam no contexto de sua existência. Essas relações, que são mediadas por experiências de origem autodidata - nas linguagens artísticas - consideram também uma posterior "[...] formação especializada quando a mesma se manifesta no contexto de vida daqueles homens e daquelas mulheres." (SOUZA, 2014b, p. 34-35) mantendo de modo perceptível a assunção que carrega o popular como uma escolha política.

Nesse contexto, destacamos que na produção artística latino-americana, os elementos visuais que denotam a singularidade de cada uma de suas nações, na maior parte das produções artísticas da arte, aqui tratada como popular, tem como peça fundamental a regionalidade. Segundo Amaral (2006), essas manifestações se tornam visíveis graças às diferentes expressões culturais originadas de processos interétnicos formativos hegemônicos, tanto de expressão histórica quanto contemporânea.

Para compreendermos o alcance dessa abordagem é importante que tenhamos clareza de que a cultura não é estagnada. A temporalidade em que o ser humano constitui sua historicidade tem influência significante nas transformações culturais que se desenvolvem no meio de cada grupo social. Marcada por pluralidades e hibridismos, as manifestações culturais de cada grupo refletem então uma expressividade específica, materializada a partir do modo pelo qual, as mulheres e os homens constituintes da existência desses grupos, dialogam seu contexto e existência.

Nesse sentido, para que possamos compreender a arte popular, devemos ter como elemento fundante desta discussão o grupo social do qual estamos falando para então considerar seus aspectos constituintes: compreendendo o contexto do território que ocupam, os modos como se expressam e como ordenam os processos de seu pertencimento comunitário e, que espaço as manifestações artísticas ocupam, e/ou como se manifestam, no bojo de sua cultura. Esses aspectos, que estão em constante transformação e desenvolvimento são marcados por pluralidades e hibridismos, desvelando características identitárias situadas historicamente, e envolvem uma 
construção que mesmo considerando uma coletividade específica não implica em uma homogeneidade.

Considerando o campo artístico e cultural no Brasil, Frederico Morais (2003) destaca que as características regionais da arte popular brasileira são uma resposta à tentativa de hegemonia do sistema da Arte - instituído pela ação das pessoas que o tornam cenário de um mercado - simbolicamente estruturado por raízes europeias e galhada estadunidense. Essas manifestações, muitas vezes presentes também nas produções de artistas contemporâneos, "[...] ao mesmo tempo que descentralizam a arte brasileira, criam o necessário contraponto aos modismos da arte internacional" (MORAIS, 2003, p. 64).

Nesse sentido, é necessário pontuar que compreendemos, como Merleau-Ponty (2004), que a produção artística concretiza as relações do artista com o mundo, materializando o mundo sensível em mundo visível. Nessa materialização a corporeidade encarnada da artista e do artista é indissociável da iconografia e da forma de produção, ordenando-se em acordo com os costumes e características de cada cultura.

As manifestações da arte constituem um tempo histórico, representam as pessoas que vivenciam e/ou vivenciaram essa historicidade, sendo resultado da percepção e representação de cada artista que ao dialogar com o mundo e com os outros no mundo, compartilha seu modo de pensar, viver e sentir na materialização de seu trabalho (SOUZA, 2014b), registrando sua interpretação da realidade e seu posicionamento diante do real.

O foco de realização desta pesquisa teve como alicerce a cidade de Ponta Porã, interior do estado de Mato Grosso do Sul, possuindo uma população de 77.872 habitantes (IBGE, 2010). Inicialmente habitada por Nhandevas e Caiuás, descendentes do povo Guarani, e devido às influências exercidas pela rota da Erva-Mate e pela Guerra do Paraguai, torna-se povoado e posteriormente município, sendo fundada em 25 de março de 1892 com emancipação em 18 de julho de 1912. Sua principal fonte de renda é a agricultura e a pecuária, sendo também conhecida por sua localização fronteiriça com o Paraguai, referência de compras para o estado de Mato Grosso do Sul.

Com origem remontando a meados do século XVII, a cidade de Ponta Porã (Punta Porá à época) era uma comunidade pertencente ao Paraguai, tendo em seu entorno as etnias indigne Kaiowá e Nhandeva. Após a Guerra do Paraguai, também conhecida como Guerra da Tríplice Aliança, que aconteceu entre 1864 e 1870, o Brasil passou a ter domínio sobre a região e, em acordo com Torrecilha (2004), recebe nova configuração pela chegada de migrantes gaúchos que intencionavam implantar o que na contemporaneidade se conhece por agronegócio. Segundo Nascimento (2014):

\begin{abstract}
A ocupação da região se deu devido ao fato de o Imperador Dom Pedro II, temeroso de uma possível tentativa de usurpação do território nacional, instituir uma colônia militar para guarnecer o território e sua fronteira; além de objetivar o contínuo contato da região com a Capital do Império. Ponta Porã, até 18 de julho de 1912, era um distrito secundário de Nioaque e, depois, ficou subordinado ao distrito de Bela Vista. Com a publicação - em 18 de julho de 1912 - do Decreto n. 617, passou à condição de município de Ponta Porã, deixando, assim, de ser distrito de Bela Vista. No entanto, só com a publicação do Decreto n. 820, de 29 de outubro de 1920, passou a existir oficialmente como cidade (NASCIMENTO, 2014, p. 113).
\end{abstract}

Considerando a constituição histórica de Ponta Porã, e as perspectivas que dão conta de descrições sobre a relação humana naquele espaço social, a investigação partiu de um levantamento bibliográfico com o intuito de conhecer outras investigações a 
respeito da arte popular manifesta naquela região. Esta etapa do trabalho de pesquisa se deu em nível inicial, de modo a preparar o campo teórico e relacionar a inserção que aconteceria posteriormente ao registro de outras abordagens científicas. Destacamos que o reconhecimento desses projetos tem caráter significativo no âmbito das pesquisas sobre arte na América Latina, procurando desvelar o quê, como, quando, para quê, se desenvolvem investigações nessa área.

Com a posterior inserção no campo da pesquisa, já na região fronteiriça de Mato Grosso do Sul com o Paraguai, foi descoberta a inexistência de artistas populares nos espaços públicos do ambiente urbano local, o que promoveu uma mudança na abordagem investigativa. Desse modo, o presente artigo apresenta o resultado de um processo investigativo que objetiva compreender a inexistência de artistas visuais bidimensionais na região de fronteira seca, situada no encontro entre Ponta Porã e Pedro Juan Caballero.

\section{O PERCURSO METODOLÓGICO DE ACESSO AO CAMPO DA PESQUISA}

Para a primeira etapa da coleta de dados envolvendo pesquisas no campo artístico que dialogassem com a presente investigação, foi realizado um levantamento por meio de plataformas online (CAPES, Biblioteca Digital Brasileira de Teses e Dissertações do Instituto Brasileiro de Informação em Ciência e Tecnologia, Google Acadêmico, SciELO.org - Scientific Eletronic Library Online, e o Oasisbr - Portal brasileiro de publicações científicas em acesso aberto), compreendendo como indicam Bogdan e Biklen (1994), que esse processo além de fundamentar, auxilia o desenvolvimento de uma metodologia própria, mantendo-se um distanciamento "[...] suficiente para formular os seus próprios conceitos ou para alargar o trabalho dos outros" (BOGDAN; BIKLEN, 1994, p. 215).

A busca online, publicada e/ou divulgada entre os anos de 2015 a $2016^{3}$, teve como descritor a expressão "arte popular", cujos resultados foram filtrados de acordo com a procedência (latino-americana, brasileira), a linguagem visual bidimensional (pintura, desenho, gravura etc.), a área do conhecimento (linguística, letras e arte), e com o objeto (iniciativas populares, em que a realização, comercialização e/ou exposição deu-se em ruas e espaços públicos de acesso gratuito).

O levantamento de dados realizado entre novembro e dezembro de 2016 não encontrou trabalho publicado em acordo com todos os critérios, reafirmando os resultados obtidos pelas pesquisas anteriores de Souza (2014b) e Souza e Souza (2016), confirmando a carência de pesquisas e estudos sobre a produção bidimensional popular latino-americana. No entanto, observamos publicações envolvendo uma abordagem ampliada dessa perspectiva - ambas trazendo a mulher como centro dos estudos, como se observa no quadro reproduzido a seguir (Quadro 1) e que serão apresentados na sequência.

\footnotetext{
${ }^{3} \mathrm{O}$ recorte configura-se nesse período em respeito à data de início do projeto de pesquisa que envolver a investigação PIBIC. Apesar de já existir um levantamento anterior de 2015, consideramos a necessidade de estender essa busca àquele ano por ser comum a publicação posterior de pesquisas. Destacamos ainda que não são reutilizados os dados obtidos anteriormente e nem as pesquisas desenvolvidas no conjunto investigativo que compõe este trabalho.
} 
Quadro 1: Trabalhos com o descritor "arte popular" envolvendo dados de 2015 a $2016^{4}$.

\begin{tabular}{|c|l|l|l|l|l|}
\hline ANO & TÍTULO DO TRABALHO & PALAVRAS-CHAVE & AUTORES & TIPO & PAÍS \\
\hline $\mathbf{2 0 1 5}$ & $\begin{array}{l}\text { Abordagem sobre trabalho } \\
\text { artesanal em histórias de } \\
\text { vida de mulheres }\end{array}$ & $\begin{array}{l}\text { Gênero; arte-educação; } \\
\text { histórias de vida; } \\
\text { trabalho feminino. }\end{array}$ & $\begin{array}{l}\text { Márcia Alves da } \\
\text { Silva }\end{array}$ & Artigo & BR \\
\hline $\mathbf{2 0 1 6}$ & $\begin{array}{l}\text { O nu na arte popular } \\
\text { mexicana }\end{array}$ & $\begin{array}{l}\text { Arte popular; nu; } \\
\text { mulheres feminismo; } \\
\text { México. }\end{array}$ & Eli Bartra Artigo & BR \\
\hline
\end{tabular}

Fonte: Portfólio dos pesquisadores.

O texto de Márcia Alves da Silva (2015), Abordagem sobre trabalho artesanal em histórias de vida de mulheres, investiga o processo de construção das identidades de gênero considerando reflexões de mulheres artesãs, vinculadas a uma cooperativa localizada na cidade de Pelotas, e de um grupo de acadêmicas do curso de Pedagogia da Universidade Federal de Pelotas (UFPel), que produzem artesanato (crochê, tricô etc.). Para desenvolvimento da pesquisa, foram criadas as Oficinas de Criação Coletiva no espaço da própria Universidade, objetivando auxiliar o resgate de memórias pelas mulheres a partir de trajetórias vividas e da produção artesanal.

A autora (SILVA, 2015) destaca ainda que o artesanato é excluído do mercado de trabalho tanto por não se adequar à produção de massa como por ser um trabalho predominantemente executado por mulheres, considerando que um discurso de viés machista atribui os "trabalhos manuais" como fundamentais no exercício da feminilidade. De acordo com o texto as mulheres que fazem parte da pesquisa buscam pela visibilidade e valorização de seus trabalhos artesanais, superar esse olhar preconceituoso e discriminatório, atribuindo às suas práticas artesanais a força de um instrumento de libertação, pela criatividade, autonomia e formação política.

Em um contexto latino-americano, no texto de Eli Bartra (2016), O nu na arte popular mexicana, encontramos uma pesquisa sobre representação do nu feminino na arte popular mexicana contemporânea. No trabalho observa-se a oposição entre o nu idealizado e o nu realista, abordada pela autora destacando a valorização das artes eruditas frente à arte popular, sendo esta última restrita a livros, museus e galerias especializados neste foco específico ${ }^{5}$. Ainda sobre a especificidade do tema abordado por sua autora, é significativo apresentar a compreensão da mesma para essa escolha. Segundo Bartra (2016, p. 16):

\begin{abstract}
Gostaria, no entanto, de esclarecer que é possível falar do nu e da nudez como duas coisas diferentes. $\mathrm{O}$ primeiro se refere, de preferência, a um corpo estático, estético, idealizado e coisificado, que como diz o historiador de arte Kenneth Clark $^{6}$ (1964, p. 3), não tem vergonha de si mesmo. O segundo é o corpo despojado de roupa, com frequência em movimento, que pode ser estético mas menos idealizado, mais "real", e está exposto ao constrangimento. Na arte popular os nus são escassos, predomina a nudez.
\end{abstract}

\footnotetext{
${ }^{4}$ Uma terceira publicação foi apresentada no relatório final do PIBIC (RODRIGUES; SOUZA, 2017) que originou a produção deste artigo, no entanto, considerando a pouca relevância daqueles dados para o corpo da atual investigação, uma vez que não contempla produções das artes visuais, o mesmo foi descartado neste trabalho.

${ }^{5}$ Destacamos que no México o termo arte popular faz referência quase que exclusiva a produções que representam uma produção artesanal de objetos artísticos.

6 A autora utiliza como fonte de referência o livro do escritor londrino Kenneth Clark: The nude, publicado originalmente em 1964.
} 
Na abordagem de Bartra (2016) a nudez e o nu na representação materializada por artistas populares desvelam-se em um tema: a sereia (Figura 1) e duas estruturas: o nu religioso e o nu lascivo. A autora destaca que as representações das sereias nas peças artísticas, tem quase nenhuma ou muito pouco apelo erotizado, tendo como apelo poético o simbolismo alegórico dessas figuras mitológicas.

Figura 1: Angélica Vázquez (México, 1958). Sirena, s.d. Cerâmica, s.m.

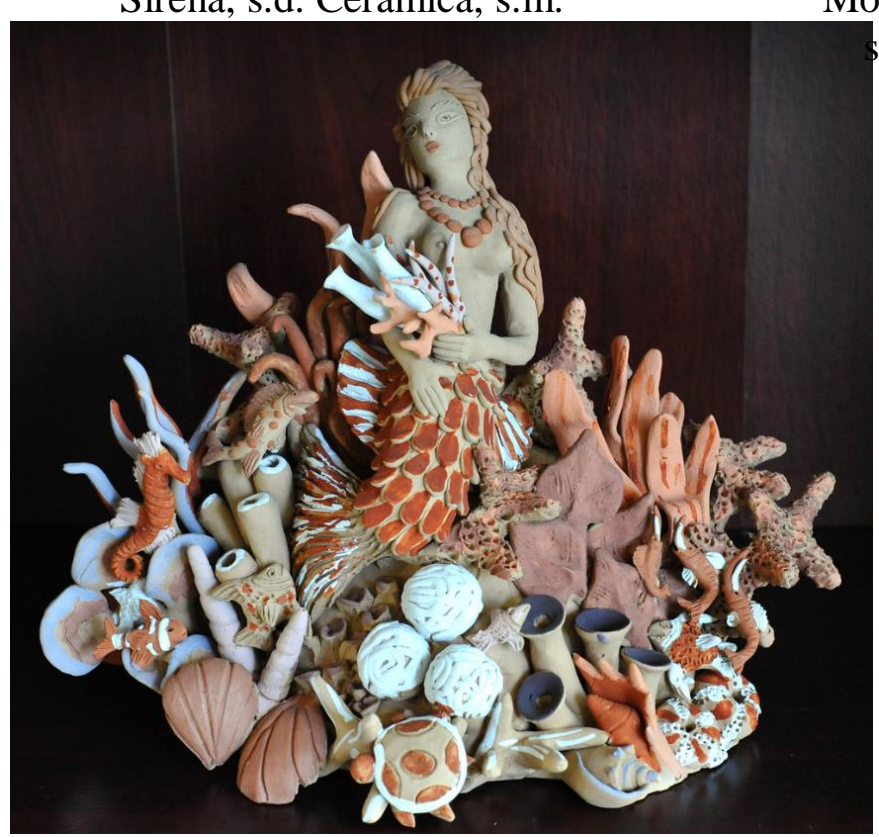

Fonte: https://www.pinterest.co.uk/
Figura 2: Gregorio Mercado Morgan (México, 19??). Bodage, d. Barro policromado, s.m.

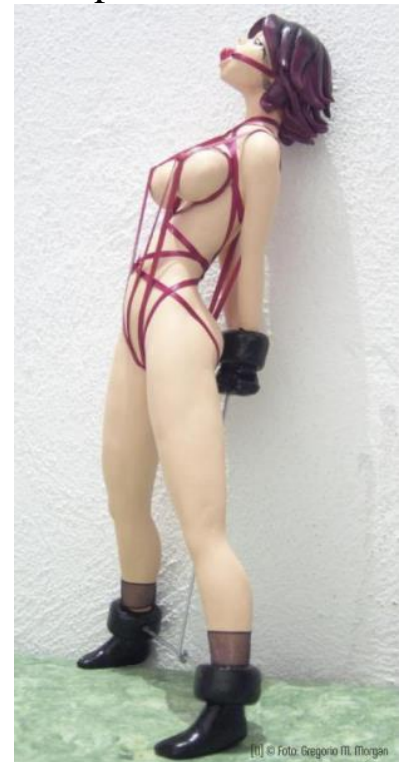

Fonte: Huerta (2018).

Nesse aspecto, Bartra (2016) destaca a diferença na representação do nu especificamente o feminino, quando produzidas por mulheres e quando produzidas por homens (Figura 2), sendo perceptível a idealização do corpo feminino, visivelmente erotizado (vale ressaltar que a autora aponta exceções nessa caracterização, tanto na produção de mulheres quanto de homens). Além dessas abordagens, a autora também descreve as representações encontradas em produções da neoarte popular. Segundo a autora, essas manifestações envolvem um conjunto composto por:

[...] todos os objetos que não se inserem na tradição artesanal de alguma comunidade. Tendem a ser urbanos, estritamente da perspectiva do mercado. Se bem que também nas diferentes comunidades que se dedicam à produção de algum tipo de objetos de arte popular mais tradicional surge de repente uma produção diferente, "moderna", poder-se-ia dizer que buscando outro tipo de consumo. A variedade dentro desse ramo é enorme e sua produção se observa em todo o território nacional (BARTRA, 2016, p. 25).

Nesse mesmo sentido, Frederico Morais (2003) elabora uma reflexão a respeito da produção de artistas contemporâneos que se apropriam da visualidade das obras de origem popular (colchas de retalhos, padrões geométricos etc.), mesmo sem apelo existencial com esse tipo de produção, porém, justificando a escolha poética como uma quebra de barreiras entre a arte erudita e a arte popular. No entanto, gostaríamos de esclarecer que na maior parte dos casos, quando se pergunta a esses artistas se existe 
uma aproximação entre suas produção e expressões de cunho regional (ou popular), a recusa é uma constante.

$\mathrm{Na}$ segunda etapa da coleta de dados, nos organizamos com outros membros do Núcleo de Investigação de Fenomenologia em Artes (NINFA), e fomos até a cidade de Ponta-Porã, fronteira do estado de Mato Grosso do Sul com Pedro Juan Caballero no Paraguai, em pesquisa de campo a fim de identificar a existência ou a ausência de manifestações bidimensionais (preferencialmente pintura), visando à compreensão dos processos criativos que, materializados em seus trabalhos, denotassem identidades específicas da região. Com duração de sete dias na região da fronteira Brasil/Paraguai, de 04 a 10 de abril de 2017, a pesquisa de campo teve sua organização programada em reuniões anteriores, com todo o grupo, a fim de, por contatos via internet (em sites de notícias da região, matérias publicadas por instituições locais, programas de televisão disponibilizados online e, pelos sítios institucionais de apoio à cultura, também na região), identificar sujeitos, cujo perfil correspondesse à nossa investigação.

Em Ponta Porã, local que tomamos como base para descanso após os dias percorrendo a cidade brasileira e sua vizinha paraguaia Pedro Juan Cabellero ${ }^{7}$, diariamente era realizada a ordenação dos dados coletados: em fotos, folders, panfletos, que abarcaram o percurso investigativo desenvolvido em cada dia, além da conferência das anotações instrumentalizadas pelo registro em diários de campo (BOGDAN; BIKLEN, 1994). Como não encontramos nenhum referencial específico da presença de artistas visuais através das publicações consultadas, iniciamos o trabalho de campo por uma caminhada objetivando sondar os espaços públicos onde geralmente essas pessoas produzem, comercializam ou expõem suas produções.

Sem identificar nenhum artista nesses locais, partimos para o contato com representantes institucionais da arte e cultura locais, incluindo aqui um artista da cidade de Pedro Juan Caballero que poderia oferecer alguma indicação. No entanto, após todas as inserções descobrimos que as manifestações artísticas envolvendo a pintura, de caráter popular e nos espaços públicos, eram inexistentes.

Inicialmente frustrados com a realidade identificada neste primeiro momento e, após um longo diálogo a respeito dos dados coletados anteriormente, da organização que estruturamos para o contato in loco, das hipóteses elaboradas a partir do levantamento do tema nas pesquisas on-line, consideramos a possibilidade de abandonar o campo e desistir da investigação. Porém, instigados pela curiosidade epistemológica sobre a inexistência de artistas populares com prática bidimensional em uma cidade de visitação humana intensa, principalmente por conta do comércio, resolvemos reorganizar nosso trabalho e compreender potenciais motivos deflagradores desse fenômeno na região de fronteira entre Paraguai e Brasil.

Considerando essa decisão nos reorganizamos para dialogar com representantes da Fundação de Cultura de Ponta Porã e com representantes de uma instituição de ensino superior voltada para a formação em artes visuais, que naquele momento histórico estava formando sua última turma. Em acordo com informações de representante daquela instituição, o curso não estava mais conseguindo atingir o número mínimo de alunos para abertura de turma novas.

Os dados utilizados para o desenvolvimento desse estudo foram obtidos pelo registro em cinco Diários de Campo produzidos no contato com nossos interlocutores. Nesse contexto, tivemos a oportunidade de conversar com pessoas de diferentes profissões relacionadas com a área de Arte, possuindo formação acadêmica e/ou prática sobre a arte popular. Considerando que a análise parte da produção de registros pessoais

\footnotetext{
${ }^{7}$ De modo paralelo a essa investigação, desenvolveu-se uma pesquisa irmã, também voltada ao projeto de pesquisa (SOUZA, 2014a) na cidade de Pedro Juan Caballero (DECKNIS; SOUZA, 2017).
} 
dos investigadores, essas pessoas não são identificadas no corpo artigo, de modo a preservar suas identidades e os espaços onde trabalham.

Quadro 2: Quadro de identificação das pessoas que colaboraram com a pesquisa.

\begin{tabular}{|l|c|c|l|c|}
\hline Identificação & Gênero & Faixa etária & Formação em Artes Visuais & Atuação na área \\
\hline Depoente 1 & Masc. & $30-40$ & Área a fim & Gestão \\
\hline Depoente 2 & Masc. & $40-50$ & Área a fim & Ensino e Poética \\
\hline Depoente 3 & Masc. & $60-70$ & Formação docente na área & Ensino e Poética \\
\hline Depoente 4 & Masc. & $40-50$ & Sem formação & Comercial e Poética \\
\hline Depoente 5 & Fem. & $20-25$ & Formação fora da área & Eventual em Poéticas \\
\hline Depoente 6 & Masc. & $30-40$ & Formação docente na área & Ensino e Gestão \\
\hline
\end{tabular}

Fonte: Portfólio dos pesquisadores.

Os depoentes 3, 4 e 5 têm nacionalidade e residência fixa no Paraguai, prestando serviços ou desenvolvendo sua prática profissional também no Brasil. Essa condição os tornou aptos a integralizar o grupo de interlocutores que tiveram seus encontros registrados em nossa investigação.

O procedimento envolvendo a análise dos Diários de Campo contemplou uma série de leituras buscando encontrar inicialmente, convergências nos registros obtidos, sem necessariamente configurar uma homogeneidade de opiniões, posto que esse tipo de resultado seria impraticável, considerando-se que mesmo em um só grupo social, as opiniões divergem sob formas e ordenações específicas (AMARAL, 2006; BOGDAN; BIKLEN, 1994). Após as leituras iniciais e a reunião dos registros que apontavam especificamente o discurso dos Depoentes, os excertos foram organizados em função do contexto de seu registro.

O processo de coleta de dados aconteceu seguindo uma organização previamente estruturada como um plano geral e, posteriormente adaptada em decorrência das informações locais que obtivemos com os próprios interlocutores da pesquisa. Destacamos que todas as conversas - que tiveram apontamentos registrados nos Diários de Campo, aconteceram nos locais de trabalho profissional dos depoentes ou em suas residências. A única exceção foi com a Depoente 5, que conhecemos e com quem pudemos dialogar quando a mesma visitava o Depoente 3 , com quem havíamos acordado um segundo encontro.

\section{APRESENTAÇÃO DOS RESULTADOS}

Em nossos registros, observamos que o olhar dos depoentes 1 e 2, que prestam serviço em instituições voltadas para a arte e a cultura, têm pouco ou nenhum contato com as artes visuais e compreendem a área em níveis de hierarquia na qual a primeira representante é a Música. Durante nosso contato, o Depoente 1 lamentou não poder colaborar e sugeriu outra aproximação, destacando que sua contribuição também seria enviesada, pois se considera retentor de "[...] um olhar mais elitista, com uma concepção de arte que se restringe apenas ao que é erudito, considerando as outras manifestações artísticas como não arte” (DIÁRIO 2, 2017, p. 6).

Em conversa posterior com o Depoente 2, este declarou que não existe um “[...] mapeamento dos artistas da cidade e ele mesmo não possui conhecimento sobre nenhum artista popular local" (DIÁRIO 2, 2017, p. 6). Este mesmo colaborador tem, no registro de sua fala, a definição de arte popular como "[...] uma arte 'alternativa', enquanto as artes plásticas são uma arte 'sofisticada', 'consolidada"” (DIÁRIO 2, 2017, p. 6). 
Segundo o Depoente 3 essa ausência pode ser compreendida por conta do pouco incentivo para as artes visuais na região e relata que:

[...] foram feitos alguns cursos/oficinas para a população, mas aqueles que participaram não demonstraram interesse na produção e comercialização, e o que existe na região é apenas o artesanato. Ele lamenta esse desinteresse e diz que há muito tempo se preocupa com essa situação e que procura formas para tentar incentivar a produção e comércio de arte (DIÁRIO 1, 2017, p. 4).

Os relatos que demarcam uma diferenciação entre as abordagens do campo artístico, principalmente quando trazemos para essa reflexão os apontamentos deflagrados tanto nas pesquisas de Silva (2015) e Bartra (2016), quanto nas reflexões compartilhadas por Morais (2003) e Amaral (2006) desvelam uma separação de cunho ideológico. Nesse mesmo sentido, ao analisar o processo artístico por meio de um modelo estrutural socioeconômico, para o qual um sistema estético burguês caracterizou três áreas: arte elitista; arte para as massas; arte popular, Canclini (1980) destaca que "A fluidez com que as mensagens artísticas passam dos canais de elite para os de massa e para os populares, ou ao contrário, demonstra a dificuldade de separar de forma maniqueísta o popular do que não o é" (CANCLINI, 1980, p. 50).

Em postura que apresenta convergências com esse posicionamento, o Depoente 4 afirma, em acordo com nossos registros, diz ser impossível viver exclusivamente de arte na região. Segundo ele:

[...] o artista não é valorizado e que ele só produz quando possui tempo e vontade, pois segundo o mesmo se ele se dedicar fazendo arte vai morrer de fome, porque as pessoas não compram, não valorizam [...]. O depoente possui muitos livros de pintura que utiliza para estudar, e nos conta quem quando se sente disposto para criar livremente, gosta de produzir arte abstrata, paisagem e natureza morta, porém apenas consegue vender retratos produzidos por encomenda (DIÁRIO 4, 2017, p. 10).

É significativo demarcar aqui, a existência de uma preocupação institucional na promoção de um desenvolvimento cultural específico na cidade de Ponta Porã, uma vez que na própria Fundação de Cultura (localizada na antiga estação ferroviária da cidade), pudemos observar a participação de jovens em projetos envolvendo uma orquestra, um projeto esportivo onde se praticavam exercícios de condicionamento físico e um terceiro com as práticas de ginástica e dança. Segundo o Depoente 3: "[...] atualmente Pedro Juan realiza mais eventos e valoriza mais a arte do que a população de Ponta Porã. As artes plásticas são menores nas escolas, mas a dança e o teatro são fortes, mesmo sem incentivo e interesse político e social" (DIÁRIO 4, 2017, p. 12) porém, o mesmo interlocutor considera que o incentivo institucional que Ponta Porã recebe de órgãos de fomento do governo são responsáveis por um desenvolvimento cultural maior. Para a Depoente 5, essa situação é mais complexa. Ela diz que:|

[...] o investimento local em artes visuais que é fraco, mas que esse investimento também passa pelo desinteresse da população. Segundo a depoente existem muitos artistas na região, mas eles não divulgam seus trabalhos, permanecendo "escondidos" em Pedro Juan e Ponta Porã (DIÁRIO 4, 2017, p. 12).

No âmbito dessa relação socioeconômica, o Depoente 3 destaca no Diário 4 (2017), que o desequilíbrio cultural e artístico na região fronteiriça de Pedro Juan e 
Ponta Porã teve seu ponto central entre os anos de 1960 e 1970. Segundo ele "[...] a arte ajuda a abrir novos horizontes e isso não é bom pro governo" (DIÁRIO 4, 2017, p. 11).

No mesmo contexto, dois dos interlocutores de nossa investigação sinalizam um período histórico em que o cenário artístico era outro. De 1972/73, até meados dos anos 2000 (DEPOENTE 4, DIÁRIO 4, 2017), os movimentos artísticos eram frequentes:

[...] antes da divisão do estado, anos de 1972/1973, existia um grupo de 3 ou 4 pessoas criado pelo artista paraguaio Julio César Alvarez Sosa que realizava eventos artísticos/culturais e cursos em Ponta Porã e em Pedro Juan, com mais intensidade em Ponta Porã. Uma dessas ações foi a abertura da Casa dos Artesãos, mas quando Julio Alvarez se mudou para Campo Grande o grupo acabou (DEPOENTE 3, DIÁRIO 4, 2017, p. 11).

Em vários momentos nos diálogos desenvolvidos com os participantes, surgiram questões envolvendo um simbolismo nas relações fronteiriças que seriam quase impossíveis de se notar (DEPOENTE 5, Diário 4, 2017). Segundo o Depoente 3 (DIÁRIO 1, 2017, p. 5):

[...] a mistura entre as culturas dessa fronteira em que as cidades são interligadas torna difícil definir onde "termina" uma e "começa" a outra, e o depoente discorre sobre uma possível "cultura de fronteira", responsável pela não existência e impossibilidade dessa delimitação, pois segundo o depoente [...] elas se misturam. [...] segundo o depoente, diante a situação de fronteira não se pode falar em uma divisão, mas também não se pode falar de união Brasil/Paraguai, existindo porém, um patriotismo que se verifica na unidade cultural/artística entre Ponta Porã e Pedro Juan.

Essa abordagem conflituosa das relações de aproximação e distanciamento na fronteira entre os dois países aparecem em outras reflexões anotadas nos Diários de Campo, desde o destaque quanto ao uso do ensino público brasileiro por crianças paraguaias (DEPOENTE 3, DIÁRIO 1, 2017), até denúncias sobre "invasões de terras" (DEPOENTE 2, DIÁRIO 2, 2017) por pessoas de origem paraguaia. Em acordo em esse interlocutor, essa tensão pode ser compreendida se considerarmos que:

[...] os desdobramentos da Guerra do Paraguai ainda são muito presentes, existindo uma união e uma separação simultaneamente; a "separação" é uma herança da guerra, segundo ele, após a guerra o Paraguai fica com a parte ecológica e histórica e Ponta Porã fica com a música. Mas essas delimitações e acordos não são tão simples na prática como na teoria, [...]; o próprio funcionário admite que até hoje essas relações são de conflito (DEPOENTE 2, DIÁRIO 3, 2017, p. 7).

A tensão na representação social/cultural que se constitui desde a percepção das pessoas que vivem na região fronteiriça, vão ao encontro da necessidade em se reconhecer - como uma forma de respeito - as distinções entre povos e comunidades. Como pontua Nascimento (2014):

[...] o contato em regiões de fronteira não pode ser visto - tão somente através de lentes românticas, que vislumbram a interação sem embates, sem dissidências, destituída de preconceitos e arrogância mútua entre os envolvidos. Tal paraíso fictício é engendrado por muitos intelectuais, dentre eles pesquisadores das mais diversas áreas do conhecimento, escritores, artistas, poetas. O objetivo, presume-se, apesar de louvável, é ingênuo e inócuo: elaborar uma noção de fronteira onde a irmandade é o mote, onde não existem fronteiras culturais; tal empreendimento desconsidera as 
injunções e ingerências políticas que se fazem presentes no cotidiano das pessoas (NASCIMENTO, 2014, p. 115-116).

A reprodução desse discurso romantizado que é comum na fala de pessoas distantes à realidade do espaço vivido na região fronteiriça, parece velar uma série de limitações e dificuldades expressivas, principalmente no que diz respeito às expressões de arte urbana. Essa situação nos chamou a atenção no primeiro contato com a região, cujo registro aponta que:

Não existem, ou pelo menos não encontramos, manifestações artísticas urbanas na cidade. Encontramos apenas um grafite muito desbotado. As poucas esculturas existentes retratam a Guerra do Paraguai. Logo, não existe contato, conhecimento, ou aproximação da população com as expressões artísticas (DIÁRIO 1, 2017, p. 4).

Segundo o Depoente 6 (DIÁRIO 5, 2017) dentre as poucas oportunidades que a população de Ponta Porã tem para entrar em contato com manifestações artísticas visuais acontecem ou por iniciativas de artistas individuais, situação também descrita pelo Depoente 3 (DIÁRIO 4, 2017) ou por exposições acadêmicas de estudantes do único curso de artes visuais na região. Nas anotações de nossa conversa, o Depoente 6 diz considerar "[...] complicada a abertura de exposições, pois além do público não possuir o hábito de apreciar a arte, existe uma desvalorização da arte por problemas culturais, desinteresse e falta de comunicação" (DIÁRIO 5, 2017, p.13).

\section{CONSIDERAÇÕES}

Considerando o entrelaçamento dos registros coletados durante a investigação na região fronteiriça de Ponta Porã e Pedro Juan Caballero, pudemos constatar que as pessoas com quem conversamos não tinham considerado a ausência de artistas populares nos espaços urbanos da região. Após encaminharmos o diálogo para a compreensão dessa ausência, os elementos principais sinalizados por nossos interlocutores refletem:

- pouco ou nenhum incentivo institucional - de origem pública para o campo das artes visuais;

- a hierarquização de uma linguagem artística sobre as demais, situando em último lugar as manifestações visuais, com destaque ao figurativo realista ou registro de paisagem;

- raras interações entre os artistas visuais com objetivo de fomentar o interesse por suas produções para a população em geral;

- a valorização romantizada da região de fronteira seca desvelada por reflexões singulares de tensão - aproximando e distanciando tanto habitantes do de Ponta Porã quanto habitantes do Paraguai, no que diz respeito à territorialidade e a um discurso ideologizado sobre identidade.

Consideramos significativo destacar que esses aspectos apenas denotam um recorte do contexto cultural da região fronteiriça entre Brasil e Paraguai. Esses dados, coletados em um contexto histórico, no entanto, são registros de pessoas cujo conhecimento e aproximação com o desenvolvimento e promoção de ações culturais na região se configura como parte de suas próprias identidades.

Mesmo com eventuais divergências sobre as manifestações artísticas que escolhem para divulgar, praticar, ensinar, suas reflexões são ordenadas por reflexões 
cuidadosas quando foram questionados sobre a arte popular local. Do mesmo modo, as considerações envolvendo o espaço geográfico - quase sempre conflituosas, também são significativas para os encaminhamentos futuros que artistas, gestores e docentes resolvam promover no âmbito das artes visuais naquela região. Desde o incentivo à organização de coletivos artísticos até uma catalogação - mesmo que simplificada, de homens e mulheres que tenham produção em artes visuais.

Ao considerar a importância dessa linguagem como um registro único da historicidade das mulheres e homens, sua cultura, seu sonhos, suas realizações, o cotidiano, entre tantas possibilidades existenciais, é possível que as divergências a respeito das relações humanas naquele contexto territorial possam ser superadas. Nesse sentido, que se considere também a legitimidade das expressões de cunho popular, considerando que:

O que, atualmente, pode ajudar-nos a identificar o caráter popular de uma prática artística é que seja, ou represente, uma resposta solidária a uma necessidade coletiva, isto é, que forme e expresse a consciência compartilhada de um conflito e contribua para superá-lo (CANCLINI, 1980, p. 77).

De forma geral, a mudança no foco da pesquisa que inicialmente se voltava para uma busca de significação da produção de artistas populares bidimensionais na região fronteiriça, ganhou maior substância para o enfrentamento das discussões que buscam romantizar a expressão artística naquele espaço. O cenário desvelado pela compreensão da inexistência dessas pessoas naquela região, carrega em si a denúncia de uma construção ideológica responsável por essa invisibilidade, pois o anúncio de que esses artistas existem foi realizado, basta agora que se reduza o interesse pelo que se convenciona potencializar como "melhor" - por exemplo as manifestações convencionalmente identificadas como eruditas - e valorizar a intencionalidade criadora daquelas e daqueles que também são responsáveis pela manutenção e continuidade das culturas: o povo.

\section{REFERÊNCIAS}

AMARAL, A. A. Textos do Trópico de Capricórnio: artigos e ansaios (1980-2005). São Paulo: Editora 34, 2006.

BARTRA, E. O nu na arte popular mexicana. Revista Trama Interdisciplinar, São Paulo, v. 7, n. 1, p. 16-30, 2016.

BOGDAN, R. C.; BIKLEN, S. K. Investigação qualitativa em educação: uma introdução à teoria e aos métodos. Porto: Porto Editora, 1994.

CANCLINI, N. G. A socialização da arte: teoria e prática na América Latina. São Paulo: Cultrix, 1980.

DECKNIS, P. P.; SOUZA, P. C. A. Caracterização da arte popular em Pedro Juan Caballero: identificação do campo. PIBIC 2016/2017. Universidade Federal de Mato Grosso do Sul, Campo Grande, 2017.

HUERTA, B. Raices que florecen. Son y arte para llevar, México, n. 5, p. 13, jul. 2018.

IBGE. Instituto Brasileiro de Geografia e Estatística. Cidades. 2010. Disponível em: <http://cidades.ibge.gov.br/v3/cidades/home-cidades>. Acesso em: 10 ago. 2019.

MERLEAU-PONTY, M. Fenomenologia da percepção. 3. ed. Tradução de Carlos Alberto R. de Moura. São Paulo: Martins Fontes, 2006. 
MERLEAU-PONTY, M. O olho e o espírito. In: MERLEAU-PONTY, M. O olho e o espírito seguido de A linguagem indireta e as vozes do silêncio e A Dúvida de Cézanne. São Paulo: Cosac \& Naif, 2004. p. 13-46.

MORAIS, F. O Brasil na visão do artista: o país e sua cultura. São Paulo: Prêmio, 2003.

NASCIMENTO, V. A. Fronteiriço, Brasileiro, Paraguaio ou Brasiguaio? Denominações Identitárias na Fronteira Pedro Juan Caballero (PY) e Ponta Porã (BR). Ilha Revista de Antropologia, Florianópolis, v. 16, n. 1, p. 105-137, dez. 2014.

RODRIGUES, M. C.; SOUZA, P. C. A. Identidade na arte popular de fronteira: a arte popular em Ponta Porã. PIBIC 2016/2017. Universidade Federal de Mato Grosso do Sul, Campo Grande, 2017.

SILVA, M. A. Abordagem sobre trabalho artesanal em histórias de vida de mulheres. Educar em Revista, Curitiba, n. 55, p. 247-260, 2015.

SOUZA, P. C. A. A. Arte de fronteira: significações de artistas populares, 2015. 15f. Projeto de Pesquisa. Centro de Ciências Humanas e Sociais, Universidade Federal de Mato Grosso do Sul, Campo Grande, 2014a.

SOUZA, P. C. A. O mundano e o promíscuo na arte latinoamericana: a prática social de pintores populares. 2014b. 320 p. Tese (Doutorado em Educação) - Centro de Educação e Ciências Humanas, Universidade Federal de São Carlos, São Carlos, 2014. Disponível em: <https://repositorio.ufscar.br/bitstream/handle/ufscar/2336/5840.pdf?sequence=1>. Acesso em: 10 ago. 2019.

SOUZA, S. P. B; SOUZA, P. C. A. Visualidade da arte popular: contatos iniciais em Campo Grande/MS. PIBIC 2015/2016. Universidade Federal de Mato Grosso do Sul, Campo Grande, 2016.

TORRECILHA, M. L. A fronteira, as cidades e a linha. Campo Grande: UNIDERP, 2004.

Recebido em: 15 out. 2019.

Aprovado em: 07 dez. 2019. 